\title{
MANAJEMEN DOSEN PENASEHAT AKADEMIK DALAM MENINGKATKAN MOTIVASI KULIAH MAHASISWA
}

\author{
Mardotella $^{1}$, Irwan Fathurrochman ${ }^{2}$, Sugiatno ${ }^{3}$, \\ Hamengkubuwono ${ }^{4}$, Muhammad Amin ${ }^{5}$ \\ Institut Agama Islam Negeri (IAIN) Curup ${ }^{1,2,3,4,5}$ \\ irwan@iaincurup.ac.id ${ }^{2}$
}

\begin{abstract}
ABSTRAK
Penelitian ini bertujuan untuk mengetahui manajemen dosen penasehat akademik dalam meningkatkan motivasi kuliah mahasiswa MPI STAIN Curup, Hasil penelitian menunjukan manajemen yang dilakuan oleh dosen penasehat akademik dalam meningkatkan motivasi kuliah mahasiswa Manajemen Pendidikan Islam (MPI) STAIN Curup yaitu dengan membuat planning (dosen dan mahasiswa bersama-sama membuat rencana studi mahasiswa), organizing (Pembagian dosen penasehat akademik diseimbangkan), actuating (Dosen penasehat akademik lebih aktif dalam menjalankan tugasnya), dan controlling (Dosen penasehat akademik mengawasi mahasiswa). Faktor pendukung bagi dosen penasehat akademik dalam meningkatkan motivasi kuliah mahasiswa MPI terbagi menjadi dua, yaitu dorongan dari dalam (keinginan, pembawaan individu, kesadaran, pengalaman masa lampau) dan dorongan dari luar (pujian dan hadiah, peraturan/tata tertib, paksaan, suri tauladan, mengetahui hasil, saingan/kompetisi), sedangkan faktor penghambatnya adalah manajemen waktu, ruangan, kesibukan, orang tua, dan mahasiswa.
\end{abstract}

Kata Kunci : Manajemen, Motivasi, Dosen Penasehat Akademik.

\begin{abstract}
Research aims to determine the management of academic advisors lecturers in increasing the motivation of MPI STAIN Curup student lectures, Knowing the Supporting Factors and Obstacles of Academic Advisor Lecturers in Increasing the Motivation of MPI STAIN Curup Student Lectures. The results showed that management carried out by academic advisory lecturers in increasing student motivation STAIN Curup Islamic Education Management (MPI) students, namely by making planning (lecturers and students jointly make student study plans), organizing (Distribution of academic advisor lecturers balanced), actuating (Academic advisors are more active in carrying out their duties), and controlling (Academic advisors supervise students). Supporting factors for academic advisors in increasing MPI student motivation are divided into two, namely encouragement from within (desire, individual traits, awareness, past experience) and encouragement from outside (praise and prizes, rules / regulations, coercion, coercion, role models, knowing the results, rivals / competition), while the inhibiting factors are time management, space, busyness, parents, and students.
\end{abstract}

Keywords : Management, Motivation, Academic Advisor Lecturer. 


\section{PENDAHULUAN}

Perguruan tinggi merupakan wadah bagi mahasiswa untuk meningkatkan kualitas sumber daya manusia melalui kegiatan pendidikan, pengajaran, pengabdian pada masyarakat, dan penelitian. Di dalam perguruan tinggi, mahasiswa akan mempelajari suatu disiplin ilmu yang lebih spesifik. Mahasiswa tersebut harus menempuh pendidikan di perguruan tinggi dengan batasan waktu untuk menyelesaikan studinya.

Selama kuliah setiap mahasiswa mempunyai dosen penasehat akademik (PA). Dosen tersebut berkewajiban membimbing mahasiswa agar sukses dalam studinya. Dosen penasehat akademik tidak berubah selama masih berstatus mahasiswa, kecuali dalam kondisi tertentu seperti dosen tersebut meninggal, sakit menahun atau yang sejenis. Tidak berubahnya dosen penasehat akademik dimaksudkan agar dapat memantau perkembangan studi mahasiswa. Oleh sebab itu, mahasiswa diharapkan berkonsultasi dengan dosen penasehat akademik secara reguler dan berkesinambungan.

Semangat kuliah dipengaruhi oleh motivasi, sedangkan dosen penasehat akademik merupakan faktor eksternal yang mempengaruhi motivasi kuliah. Dalam proses pembelajaran tanggungjawab pencapaian tujuan belajar selain terletak pada mahasiswa juga pada dosen penasehat akademik. Manajemen dosen penasehat akademik sebagai motivator merupakan salah satu aspek yang sangat penting untuk mencapai keberhasilan dalam pembelajarannya, dengan demikian mahasiswa termotivasi untuk melaksanakan dan mencapai tujuan pembelajaran selama menempuh pendidikan. Nento, (2019) menyebutkan bahwa Manajemen Pendidikan Islam adalah suatu proses pengelolaan lembaga pendidikan Islam secara Islami dengan cara menyiasati sumber-sumber belajar dan hal-hal lain yang terkait untuk mencapai tujuan pendidikan Islam secara efektif dan efisien (Nento, 2018). Prodi Manajemen Pendidikan Islam (MPI) Jurusan Tarbiyah Sekolah Tinggi Agama Islam Negeri (STAIN) Curup berdiri pada tahun 2014 sehingga belum adanya lulusan yang dihasilkan.

Banyaknya Mahasiswa Prodi Manajemen Pendidikan Islam (MPI) khususnya yang masih duduk di semester 2 dan 4 ingin pindah ke Prodi, Jurusan, Maupun Perguruan Tinggi yang lainnya. Baik itu karena dipengaruhi teman, kurangnya pengetahuan mengenai prosfek pekerjaannya kedepan, maupun karena salah pilih Prodi. Adapun alasan lain, diantaranya adalah adanya mahasiswa Prodi Manajemen Pendidikan Islam yang malas kuliah, sering telat, IPK yang rendah, baik itu disebabkan oleh kurangnya manajemen waktu maupun penyebab lainnya.

Motivasi merupakan unsur penting yang terdapat pada setiap individu untuk mencapai prestasi tinggi (Emda, 2018). Motivasi bisa berbeda antara individu yang terlibat didalamnya sesuai dengan situasi, tempat dan keadaan lingkungan dimana orang itu berada (Ristianti, 2015). Manusia memerlukan dorongan, arahan, gerakkan agar dapat dikendalikan untuk mencapai tujuan yang diinginkan (Anas, 2014).

(Mendari \& Kewal, 2016) menyeburkan bahwa dunia pendidikan maupun dunia kerja tentu membutuhkan pengetahuan tentang manajemen agar suatu kegiatan memiliki target dan tujuan dengan menggunakan perencanaan, pengarahan serta pengorganisasian dalam mencapai tujuan tersebut. Menjadi penting hukumnya untuk setiap mahasiswa agar bisa mengelola manajemen waktu (time management), karena manusia bukanlah mesin yang dapat melakukan 
pekerjaan secara bersamaan (multi tasking). Tentunya, time management dan kedisiplinan sangat dibutuhkan. Agar nilai kuliah tetap tinggi, hasil pekerjaan tetap maksimal dan dapat menikmati waktu, ada beberapa hal harus dipertimbangkan dengan matang seperti mengenali batasan diri, mengelola waktu, dan lain-lain.

Motivasi dalam kuliah sangat besar pengaruhnya pada hasilnya (Amin, et.al, 2019). Di dalam kegiatan belajar mengajar peranan motivasi baik intrinsik maupun ekstrinsik sangat dipelukan. Dengan motivasi, mahasiswa dapat mengembangkan aktivitas dan inisiatif, dapat mengarahkan dan memelihara ketekunan dalam melakukan kegiatan belajar. Selain dari orang tua motivasi itu juga bisa didapatkan di lingkungan sekitar, baik itu teman, guru, rekan kerja, anak-anak, begitu juga dengan dosen penasehat akademik (Palupi, et.al, 2018).

\section{METODE PENELITIAN}

Jurnal ilmiah ini ditulis menggunakan penelitian lapangan (field research), yaitu penelitian yang pengumpulan datanya dilakukan di lapangan (Ristianti, et.al, 2019). Metode penelitian yang dipakai dalam penelitian ini adalah metode penelitian kualitatif, Unit analisis dalam penelitian ini adalah Individu yang berkaitan dengan Prodi MPI, baik itu Dosen Penasehat Akademik, Ketua Prodi, Staf Prodi, Mahasiswa MPI, dan lain-lain. Teknik Penggalian Datanya adalah Observasi, Wawancara, Dokumentasi. Teknis analisis data yang lakukan adalah Reduksi Data, Penyajian Data, Penarikan Kesimpulan. Berdasarkan latar belakang masalah yang telah diuraikan, maka dapat ditarik beberapa pertanyaan penelitian, yaitu: (1) Bagaimana manajemen dosen penasehat akademik dalam meningkatkan motivasi kuliah mahasiswa MPI STAIN Curup. (2) Apakah saja faktor-faktor pendukung dan penghambat dosen penasehat akademik dalam meningkatkan motivasi kuliah mahasiswa MPI STAIN Curup (Ulfatin, 2015).

\section{HASIL PENELITIAN}

Dosen yang mengajar di Prodi MPI STAIN Curup semuanya adalah Dosen Tetap PNS dengan gambaran sebagai berikut

Table 1

Data Dosen Tetap Prodi MPI STAIN Curup

\begin{tabular}{clcl}
\hline No. & Nama Dosen Tetap & NIDN & \multicolumn{1}{c}{$\begin{array}{c}\text { Bidang Keahlian untuk Setiap } \\
\text { Jenjang Pendidikan }\end{array}$} \\
\hline (1) & \multicolumn{1}{c}{$(2)$} & $(3)$ & \multicolumn{1}{c}{$(7)$} \\
\hline 1 & Muhammad Amin, S.Ag., M.Pd & 2007086901 & $\begin{array}{l}\text { Dakwah } \\
\text { Manajemen Pendidikan }\end{array}$ \\
\hline 2 & Sugiatno, S.Ag., M.Pd & 2017107102 & $\begin{array}{l}\text { Aqidah } \\
\text { Filsafat Pemikiran } \\
\text { Pendidikan Islam }\end{array}$ \\
& & & $\begin{array}{l}\text { Dakwah } \\
\text { Aanajemen Pendidikan }\end{array}$ \\
\hline 3 & Arsil, S.Ag., M.Pd & 2019096701 & $\begin{array}{l}\text { Pendidikan } \\
\text { Kesenian } \\
\text { Manajemen Pendidikan }\end{array}$ \\
\hline 4 & Dr. Jumira Warlizasusi S.Pd., & 2025096601 & $\begin{array}{l}\text { Kependidikan Islam } \\
\text { Manajemen Pendidikan }\end{array}$ \\
& M.Pd & & \\
\hline 5 & $\begin{array}{l}\text { Irwan Fathurrochman, S.Pd., } \\
\text { M.Pd }\end{array}$ & 2026088402 & \\
\hline
\end{tabular}




\begin{tabular}{|c|c|c|c|}
\hline 6 & Drs. Syaiful Bahri, M.Pd & 2011106402 & $\begin{array}{l}\text { Syariah } \\
\text { Manajemen Pendidikan }\end{array}$ \\
\hline
\end{tabular}

Sumber: Data MPI STAIN Curup

Sedangkan untuk tenaga kependidikan meliputi tenaga administrasi umum, laboran, pustakawan dan pranata komputer. Pegawai laboran, pustakawan, dan pranata komputer masih menyatu dengan institusi STAIN Curup. Adapaun tenaga adaministrasi umum gambarannya sebagai berikut :

Table 2

Nama Pegawai Prodi MPI STAIN Curup

\begin{tabular}{ccccc}
\hline No. & Nama Pegawai & NIP & Jenjang Pendidikan \\
\hline$(1)$ & $(2)$ & $(3)$ & $(7)$ \\
\hline 1 & Eka Merdekawati & - & S1 STAIN Curup \\
\hline
\end{tabular}

Sumber: Data MPI STAIN Curup

Berikut adalah pembagian dosen pembimbing akademik yang ada di STAIN Curup :

Table 3

Nama Mahasiswa Tahun Masuk 2014 dan Dosen Penasihat Akademik

\begin{tabular}{clcl}
\hline No & \multicolumn{1}{c}{ Nama } & NIM & \multicolumn{1}{c}{ Nama Dosen PA } \\
\hline 1 & Tri Nur Sulistiana & 14561012 & Dra. Sri Rahmaningsih, M.Pd.I \\
\hline 2 & Mardotella & 14561011 & Dra. Sri Rahmaningsih, M.Pd.I \\
\hline 3 & Sandya Suci Larasati & 14561010 & Dra. Sri Rahmaningsih, M.Pd.I \\
\hline 4 & Subur Harianto & 14561008 & Dra. Sri Rahmaningsih, M.Pd.I \\
\hline 5 & Diajeng Beratasena & 14561007 & Dra. Sri Rahmaningsih, M.Pd.I \\
\hline 6 & Diki Irawan & 14561006 & Dra. Sri Rahmaningsih, M.Pd.I \\
\hline 7 & Dewi Susilawati & 14561005 & Dra. Sri Rahmaningsih, M.Pd.I \\
\hline 8 & Ovi Nency & 14561004 & Dra. Sri Rahmaningsih, M.Pd.I \\
\hline 9 & Lindiani & 14561003 & Dra. Sri Rahmaningsih, M.Pd.I \\
\hline 10 & Purnama Indah & 14561002 & Dra. Sri Rahmaningsih, M.Pd.I \\
\hline 11 & Yuyun Yuningsih & 14561001 & Dra. Sri Rahmaningsih, M.Pd.I \\
\hline 12 & Malik & 14561009 & Dra. Sri Rahmaningsih, M.Pd.I \\
\hline
\end{tabular}

Sumber: Data MPI STAIN Curup

Table 4

Nama Mahasiswa Tahun Masuk 2015 dan Dosen Penasihat Akademik

\begin{tabular}{clcl}
\hline No & \multicolumn{1}{c}{ Nama } & NIM & \multicolumn{1}{c}{ Nama Dosen PA } \\
\hline 1 & Adriansyah & 15561001 & Sugiatno, S.Ag., M.Pd \\
\hline 2 & Ayun Sundari & 15561004 & Sugiatno, S.Ag., M.Pd \\
\hline 3 & Dahlia Oktari & 15561005 & Sugiatno, S.Ag., M.Pd \\
\hline 4 & Densi Hariani & 15561007 & Sugiatno, S.Ag., M.Pd \\
\hline 5 & Diah Resida & 15561008 & Sugiatno, S.Ag., M.Pd \\
\hline 6 & Ferogita Ramadani & 15561009 & Sugiatno, S.Ag., M.Pd \\
\hline 7 & Hendri Bustami & 15561010 & Muhammad Amin, S.Ag., M.Pd \\
\hline 8 & Heris Erlangga & 15561011 & Muhammad Amin, S.Ag., M.Pd \\
\hline 9 & Joko Prayogo & 15561012 & Muhammad Amin, S.Ag., M.Pd \\
\hline 10 & Karyon Mahendra & 15561013 & Muhammad Amin, S.Ag., M.Pd \\
\hline 11 & Khairunnisa Isnaini & 15561014 & Muhammad Amin, S.Ag., M.Pd \\
\hline 12 & Krisna Bimantoro & 15561015 & Muhammad Amin, S.Ag., M.Pd
\end{tabular}




\begin{tabular}{llll}
\hline 13 & M. Djuang Manara A. & 15561016 & Muhammad Amin, S.Ag., M.Pd \\
\hline 14 & M. Jovi Debiansyah & 15561017 & Arsil, S.Ag., M.Pd \\
\hline 15 & Nandito Saputra & 15561018 & Arsil, S.Ag., M.Pd \\
\hline 16 & Radha Krisna Putri & 15561021 & Arsil, S.Ag., M.Pd \\
\hline 17 & Resti Atika & 15561022 & Arsil, S.Ag., M.Pd \\
\hline 18 & Ricky Irawan & 15561023 & Arsil, S.Ag., M.Pd \\
\hline 19 & Wahyu Trio Oktora & 15561025 & Arsil, S.Ag., M.Pd \\
\hline 21 & Angga Riansyah & 15561002 & Arsil, S.Ag., M.Pd \\
\hline 22 & Niska Putri Utami & 15561024 & Dra. Sri Rahmaningsih, M.Pd.I \\
\hline 23 & Anisa Zukia & 15561019 & Dra. Sri Rahmaningsih, M.Pd.I \\
\hline 24 & Pio Andeko & 15561003 & Dra. Sri Rahmaningsih, M.Pd.I \\
\hline 25 & Aji Ilham & 15561020 & Dra. Sri Rahmaningsih, M.Pd.I \\
\hline
\end{tabular}

Sumber: Data MPI STAIN Curup

Table 5

Nama Mahasiswa Tahun Masuk 2016 dan Dosen Penasihat Akademik

\begin{tabular}{clll}
\hline No & \multicolumn{1}{c}{ Nama } & NIM & \multicolumn{1}{c}{ Nama Dosen PA } \\
\hline 1 & Adam Supratman & 16561001 & Abdul Sahib, M.Pd \\
\hline 2 & Amdrian Febri & 16561002 & Abdul Sahib, M.Pd \\
\hline 3 & Deni Hermawan & 16561003 & Abdul Sahib, M.Pd \\
\hline 4 & Dika Aryani & 16561004 & Muhammad Amin, S.Ag., M.Pd \\
\hline 5 & Eko Febriyanto & 16561005 & Muhammad Amin, S.Ag., M.Pd \\
\hline 6 & Eko Setio & 16561006 & Muhammad Amin, S.Ag., M.Pd \\
\hline 7 & Ira Lestari & 16561007 & Muhammad Amin, S.Ag., M.Pd \\
\hline 8 & Lingkaran Sakti & 16561008 & Murniyanto \\
\hline 9 & Oki Kurnia Saputra & 16561009 & Dra. Sri Rahmaningsih, M.Pd.I \\
\hline 10 & Putri Susanti & 16561010 & Dra. Sri Rahmaningsih, M.Pd.I \\
\hline 11 & Ranum Wijaya & 16561011 & Dra. Sri Rahmaningsih, M.Pd.I \\
\hline 12 & Reva Pransiska & 16561012 & Sugiatno, S.Ag., M.Pd \\
\hline 13 & Rina Oktaria & 16561013 & Sugiatno, S.Ag., M.Pd \\
\hline 14 & Ropika Sari & 16561014 & Sugiatno, S.Ag., M.Pd \\
\hline 15 & Sari Fatimah & 16561015 & Murniyanto \\
\hline 16 & Susi Ratna Sari & 16561016 & Arsil, S.Ag., M.Pd \\
\hline 17 & Wahyu Ningsih & 16561017 & Murniyanto \\
\hline 18 & Wahyu Ramadhani & 16561018 & Arsil, S.Ag., M.Pd \\
\hline 19 & S. Nudia Mastur & 16561019 & Arsil, S.Ag., M.Pd \\
\hline Sura & &
\end{tabular}

Sumber: Data MPI STAIN Curup

Table 6

Nama Mahasiswa Tahun Masuk 2017 Dosen Penasihat Akademik

\begin{tabular}{clll}
\hline No & \multicolumn{1}{c}{ Nama } & NIM & \multicolumn{1}{c}{ Nama Dosen PA } \\
\hline 1 & Ahmad Busroni & 17561001 & Arsil, S.Ag., M.Pd \\
\hline 2 & Ali Muslimin & 17561002 & Abdul Sahib, M.Pd \\
\hline 3 & Angga Dwi Saputra & 17561003 & Abdul Sahib, M.Pd \\
\hline 4 & Benni AG & 17561004 & Abdul Sahib, M.Pd \\
\hline 5 & Dioba Ade Apriyanto & 17561005 & Dra. Sri Rahmaningsih, M.Pd.I \\
\hline 6 & Elva Riza & 17561006 & Irwan Faturrochman, M.Pd \\
\hline 7 & Erik Suyatmo & 17561007 & Irwan Faturrochman, M.Pd \\
\hline 8 & Hafiz Aljufri & 17561008 & Irwan Faturrochman, M.Pd \\
\hline 9 & Hardiantarai Swan Danu & 17561009 & Dra. Sri Rahmaningsih, M.Pd.I \\
\hline 10 & Hengkin Saputra & 17561010 & Muhammad Amin, S.Ag., M.Pd \\
\hline 11 & Ira Widiawati & 17561011 & Muhammad Amin, S.Ag., M.Pd \\
\hline 12 & Karimatun Nafia & 17561012 & Muhammad Amin, S.Ag., M.Pd \\
\hline
\end{tabular}




\begin{tabular}{llll}
\hline 13 & Maya Sari & 17561013 & Muhammad Amin, S.Ag., M.Pd \\
\hline 14 & Muhammad Arifin & 17561014 & Muhammad Amin, S.Ag., M.Pd \\
\hline 15 & Nova Putri Yani & 17561015 & Muhammad Amin, S.Ag., M.Pd \\
\hline 16 & Rahmadani Anwar & 17561016 & Sugiatno, S.Ag., M.Pd \\
\hline 17 & Risky Fadila & 17561026 & Sugiatno, S.Ag., M.Pd \\
\hline 18 & Redo Michel & 17561017 & Dra. Sri Rahmaningsih, M.Pd.I \\
\hline 19 & Revi Anggraini & 17561018 & Sugiatno, S.Ag., M.Pd \\
\hline 20 & Shella Ponikasari & 17561019 & Drs. Syaiful Bahri, M.Pd \\
\hline 21 & Surati & 17561020 & Drs. Syaiful Bahri, M.Pd \\
\hline 22 & Tri Jajaka Prakasa & 17561021 & Drs. Syaiful Bahri, M.Pd \\
\hline 23 & Warman & 17561022 & Dra. Sri Rahmaningsih, M.Pd.I \\
\hline 24 & Yudha Pranata & 17561023 & Arsil, S.Ag., M.Pd \\
\hline 25 & Yulian Wahyu Irawan & 17561024 & Arsil, S.Ag., M.Pd \\
\hline 26 & Yuliani & 17561027 & Arsil, S.Ag., M.Pd \\
\hline Subarat
\end{tabular}

Sumber: Data MPI STAIN Curup

Dari data dosen penasehat akademik di atas, maka adapun rekapitulasi jumlah dosen penasehat akademik dengan mahasiswa yang dibimbingnya:

Table 7

Rasio Dosen Penasihat Akademik dan Mahasiswa Bimbingan

\begin{tabular}{clc}
\hline No & \multicolumn{1}{c}{ Nama Dosen Penasehat Akademik } & $\begin{array}{c}\text { Jumlah Mahasiswa } \\
\text { Yang Dibimbing }\end{array}$ \\
\hline 1 & Dra. Sri Rahmaningsih, M.Pd.I & 24 \\
\hline 2 & Muhammad Amin, S.Ag., M.Pd & 17 \\
\hline 3 & Arsil, S.Ag., M.Pd & 14 \\
\hline 4 & Sugiatno, S.Ag., M.Pd & 12 \\
\hline 5 & Abdul Sahib, M.Pd & 6 \\
\hline 6 & Murniyanto & 3 \\
\hline 7 & Drs. Syaiful Bahri, M.Pd & 3 \\
\hline 8 & Irwan Faturrochman, M.Pd & 3 \\
\hline
\end{tabular}

Sumber: Data MPI STAIN Curup

\section{PEMBAHASAN}

\section{Planning/perencanaan}

Perenacanaan dalam kegiatan penasehat akademik dilakukan dengan melakukan pemahaman yang sama terkait perencanaan yaitu dosen penasehat akademik membantu mengarahkan rencana studi yang akan diambil agar mahasiswa tidak mengambil mata kuliah di luar batas maksimal dan akhirnya mampu menyelesaikan bebannya dengan baik. Perencanaan yang dibuat oleh dosen penasehat akademik sebenarnya adalah sebagaimana dosen penasehat akademik menjalankan tugas dan tanggungjawab dosen penasehat akademik, sehingga mahasiswa dapat menyelesaikan studinya tepat waktu.

Perencanaan dosen penasehat akademik dalam meningkatkan motivasi kuliah mahasiswa Manajemen Pendidikan Islam sebenarnya sudah terterang di dalam buku konsultasi dan kegiatan kokurikuler mahasiswa, dosen penasehat akademik hanya menambahkan beberapa rencana yang akan lebih mendukung kegiatan mahasiswa. Dosen penasehat akademik dan mahasiswa biasanya membuat perencanaan di awal perkuliahan atau masa pergantian semester agar diakhir semester dapat dilihat apakah rencana yang sudah dibuat sudah tercapai atau belum. 
Perencanaan yang dijalankan oleh dosen penasehat akademik sudah baik. Perencanaan dosen penasehat akademik adalah rencana yang ditentukan dalam meningkatkan keberhasilan studi mahasiswa, rencana tersebut bertujuan untuk mengatasi segala permasalahan mahasiswa, membantu pengambilan mata kuliah, dan membimbing mahasiswa agar hak-hak yang mahasiswa perlukan terpenuhi sejauh yang dibutuhkannya. Perencanaan tersebut agar mahasiswa lebih termotivasi untuk kuliah, dan penyelenggaraan sistem pendidikan menjadi efektif dan efesien, serta menghasilkan lulusan yang lebih bermutu.

\section{Organizing/pengorganisasian}

Organizing oleh Prodi Manajemen Pendidikan Islam STAIN Curup tentang pembagian dosen penasehat akademik dengan mahasiswa yang dibimbing belum dibagi dengan seimbang, tetapi berdasarkan hasil observasi pembagian dosen penasehat akademik sudah baik karena dosen penasehat akademik tidak hanya membimbing mahasiswa yang ada di Prodi Manajemen Pendidikan Islam. Hal ini senada dengan yang dikemukakan oleh Bapak Muhammad Amin, sebagai ketua Prodi Manajemen Pendidikan Islam STAIN Curup mengenai pengorganizingan dosen penasehat akademik Manajemen Pendidikan Islam STAIN Curup Pengorganisasian dosen penasehat akademik Manajemen Pendidikan Islam STAIN Curup sudah baik karena jumlah dosen penasehat akademik dengan mahasiswa sudah dibagi rata, tidak ada dosen penasehat akademik yang memegang/membimbing terlalu banyak mahasiswa, sehingga dosen penasehat akademik dapat memaksimalkan waktunya untuk mahasiswa PA yang telah ditentukan. Jika dosen penasehat akademiknya membimbing banyak mahasiswa di Prodi MPI maka di Prodi lain sedikit, begitu juga sebaliknya. Dosen Penasehat Akademik membimbing 20 Mahasiswa setiap tahunnya.

\section{Actuating/Aktualisasi}

Dosen memiliki karakteristik yang berbeda-beda dalam membimbing mahasiswanya. Di lapangan sudah banyak peneliti temui dosen penasehat akademik yang sudah menjalankan tugasnya dengan baik, tetapi masih ada juga yang belum berjalan dengan baik, beberapa dosen penasehat akademik kurang peduli dengan mahasiswanya, sehingga mahasiswa sendiri harus lebih aktif dalam mencari dosennya Manajemen pelaksanaan dosen penasehat akademik sudah berjalan dengan baik karena dosen penasehat akademik sudah mempermudah kesempatan mahasiswa berkomunikasi langsung, tidak mempersulit permasalahan yang dihadapi mahasiswa, mahasiswapun selalu diarahkan dan dibimbing sehingga tidak keliru dalam menghadapi permasalahan-permasalahan yang ditemukan.

\section{Controlling/Pengawasan}

Dosen penasehat akademik telah melakukan pengawasan dengan mahasiswa. Pengawasan itu dilakukan oleh dosen penasehat akademik baik secara langsung maupun tidak langsung. Pengawasan secara langsung seperti dosen penasehat akademik memanggil mahasiswanya, melihat perkembangan hasil belajarnya, dosen penasehat akademik melihat keaktifan mahasiswa saat belajar sedangkan pengawasan secara tidak langsung adalah dosen penasehat akademik menanyakan keaktifan mahasiswa di lokal dengan dosen yang mengajar, dan lain- 
lain. Pengawasan sangat perlu dilakukan agar mahasiswa tidak melakukan permasalahan selama kuliah.

Para dosen penasahat akademik Manajemen Pendidikan Islam selalu berusaha untuk memberikan pengawasan terhadap setiap aktivitas yang dilakukan oleh mahasiswa di kampus, karena apa yang dilakukan mahasiswa di kampus merupakan tanggungjawab dosen penasehat akademik. Untuk dosen penasehat akademik mengawasi permasalahan mahasiswa selama kuliah, baik itu pengambilan mata kuliah/pengisian Kartu Rencana Studi (KRS), Setoran Pembayaran Perkuliahan (SPP), Indeks Prestasi Kumulatif (IPK), dan lain-lain. Hal ini bertujuan untuk melihat perkembangan kemajuan akademik dan meningkatkan kedisiplinan kuliah mahasiswa. Sari Fatimah sebagai mahasiswa Prodi Manajemen Pendidikan Islam STAIN Curup, dia mengemukakan bahwa: dosen penasehat akademik selalu mengawasi perkembangan kemajuan akademik mahasiswa, jika mahasiswa tidak menghadap dosennya untuk berkonsultasi, biasanya dosen penasehat akademik akan memanggil mahasiswanya. Sehingga dosen penasehat akademik memiliki pengaruh yang sangat besar dalam studi mahasiswa. Selanjutnya Bapak Murniyanto sebagai dosen penasehat akademik Prodi Manajemen Pendidikan Islam STAIN Curup, beliau mengatakan bahwa: Pengawasan adalah pengoreksian kegiatan-kegiatan mahasiswa sesuai dengan rencana yang telah ditetapkan. Dosen penasehat akademik hanya mengawasi sebatas menjalankan kewajiban sebagai mahasiswa. Pengawasan diarahkan sepenuhnya untuk menghindari adanya kemungkinan penyimpangan atau penyelewengan atas tujuan yang akan dicapai.

Pengawasan khusus yang dilakukan dosen penasehat akademik telah dijalankan dengan baik yaitu mengawasi mahasiswa dalam menjalani masa pekuliahan, hal ini bertujuan untuk mengatasi kendala-kendala yang ditemukan dalam melaksanakan perkuliahan karena dengan adanya pengawasan dari dosen penasehat akademik perkuliahan dapat berjalan dengan baik.

\section{SIMPULAN}

Penelitian ini baik secara teoritis maupun praktis menghasilkan temuan yang dapat disimpulkan bahwa manajemen yang dilakuan oleh dosen penasehat akademik dalam meningkatkan motivasi kuliah mahasiswa Manajemen Pendidikan Islam STAIN Curup yaitu dengan membuat planning (dosen dan mahasiswa bersama-sama membuat rencana studi mahasiswa), organizing (pembagian dosen penasehat akademik diseimbangkan, sehingga dosen penasehat akademik dapat fokus membimbing mahasiswa, dan dosen penasahat akademik memberikan kesempatan yang mudah untuk bertemu dengan mahasiswa), actuating (dosen penasehat akademik lebih aktif dalam menjalankan tugasnya dan mahasiswa lebih sering menemui dosen penasehat akademiknya, dan controlling (dosen penasehat akademik mengawasi mahasiswa dalam menjalankan perkuliahan agar kendala-kendala yang dihadapi mahasiswa dapat diatasi). 


\section{DAFTAR PUSTAKA}

Amin, M., Arsil, Fathurrochman, I., Bahri, S., \& Rahmaningsih, S. (2019). Manajemen Mutu Pendidikan Pada Perguruan Tinggi (1st ed.). Rejang Lebong: LP2 IAIN Curup.

Anas Muhammad, A. F. (2014). Motivasi Belajar Mahasiswa. Penelitian Pendidikan INSANI, 16(1), 41-46.

Emda, A. (2018). Kedudukan Motivasi Belajar Siswa Dalam Pembelajaran. Lantanida Journal, 5(2), 172. https://doi.org/10.22373/lj.v5i2.2838

Mendari, A. S., \& Kewal, S. S. (2016). Motivasi Belajar Pada Mahasiswa. Jurnal Pendidikan Akuntansi Indonesia, 13(2). https://doi.org/10.21831/jpai.v13i2.10304

Nento, S. (2018). Analisis Kompetensi Profesional dan Kinerja Dosen. Jurnal Ilmiah Iqra', 6(1). https://doi.org/10.30984/jii.v6i1.619

Palupi, P. R. P., Agustin, R. W., \& Satwika, P. A. (2018). Pengaruh Pelatihan Manajemen Diri terhadap Prokrastinasi Akademik Mahasiswa FK UNS dalam Menyelesaikan Skripsi. Jurnal Wacana, 1-15.

Ristianti, D. H. (2015). Pengaruh Pemahaman Mahasiswa Terhadap Program Studi Dengan Ketahanan Belajar Mahasiswa (Studi Terhadap Mahasiswa Tahun Akademik 2014/2015 Jurusan Tarbiyah STAIN Curup). Proceeding IAIN Batusangkar, 1(1), 199-212. Retrieved from http://ecampus.iainbatusangkar.ac.id/ojs/index.php/proceedings/article/view/ $689 / 669$

Ulfatin, N. (2015). Metode Penelitian Kualitatif di Bidang Pendidikan: Teori dan Aplikasinya. Malang: Media Nusa Creative. 